frog skin, muscle and kidney and in the relatively simple lipid bilayers are also included.

Teachers in a variety of biological disciplines who have taken note of the growing interest in membranes and have considered the possibility of introducing relevant practical experiments into undergraduate curricula will find that few of these experiments can be adapted to the needs of undergraduates.

Nevertheless, even if one is not in a position to practise these experimental techniques, one can still gain from this book a great deal of knowledge of membrane phenomena which is not readily available from general textbooks. The practical book which gives the essential theoretical background as well as the experimental detail often provides the most helpful source of information on specific phenomena. This book can be recommended to those who contemplate setting up postgraduate courses in this field and also to those who simply wish to gain a greater knowledge of what these important techniques of membrane biophysies involve.

J. B. Finean

\section{DONORS AND ACCEPTORS}

\section{Bioelectronics}

A Study in Cellular Regulations, Defense and Cancer. By Albert Szent-Györgyi. Pp. ix + 89. (Academic Press: New York and London, December 1968.) $46 s 8 d$.

'THIs is the third of a trilogy whose other two books were entitled Bioenergetics and Introduction to a Submolecular Biology. This book deals with electronic and bond energy charge transfer, donors and accoptors, the regulation of cell division and ends with a bricf reference to the problem of cancer.

The author considers the cell as a machine driven by energy. Molecular biochemistry failed by ignoring the non-additivity of living matter. In the hierarchy of progressive organization novel phenomena emerge. Both animate and inanimate entities obey the same natural laws, but living organisms reach much farther than nonliving molecules or atoms. Photons are the source of life; because of the plant's absorption of photons, all the necessary energy is provided in a somewhat miscrly way. Szent-Györgyi draws heavily on the Pullmans' outstanding monograph Quantum Biochemistry in which the reactivity of electrons was convincingly described. The passing of an electron to a different molecule is the so-called charge transfer. This whole field originated with Mulliken who systematized rigorously what was bitherto only qualitatively guessed. The author used this donor/ acceptor relationship by explaining those interactions by some of the fundamental biological reactions. Thus, he ascribes the tranquillizing action of chlorpromazine to its strong donor trait and the hallucinogenic behaviour of lysergic acid to electron transfer.

He claims that chargo transfer accounts for intermolecular motion of eloctrons, and energy bands for motion inside macromolecules. The conjecture seems feasible. In the chapter on charge transfer, however, he suggests that only a very small part of the electron is transferred. This way of treating the electron will not go down too well with the physicist. Analogously, we are presented with two-wave mechanical equations which cannot be solved and which are proffered for the sake of a physical (not chemical) description of charge transfer. The author agrees with Brönsted and Lewis in that acids accept electrons and bases donate them. The cell is rich in donors but comparatively poor with regard to acceptors, and any addition of acceptors may lead to a regulatory activity.

His explanation of the repair of mechanical damage in tissues, for instance, makes sense from a biochemical viewpoint. One is surprised to learn that no change in $p \mathrm{H}$ is responsible, at least in part, for cell division. But he is chiefly preoccupied with the arresting of growth without destroying vital tissue. What happens when a wound exists? Well, the exposure on the adjacent sides of the injured tissue upsets equilibria and activates glyoxalase.

I found the short chapter on cancer immensely instructive. The distinction between cancer and normal healthy cells is not the fact that cancer cells grow. The point is that normal cells cease to grow when growth is no longer required, whereas cancer cells multiply without any "brake", with uninhibited prolifcration. Yet there are cells which multiply even faster than cancer cells, which do not organize, possess no contact inhibition. 'The cancer' coll does not behave differently from a proliferating healthy cell, but the cancer cannot return to the state of rest. Biochemically speaking, cancerous cells have lost the ability to bind and inectivate glyoxalase. Ascites cancers have displayed therapeutic results in mice when locally treated with methylglyoxal. Szent-Györgyi is engaged in producing gradually an electron acceptor in tho body by onzymic action. He maintains that no permanent cure can be attained by means of glyoxal derivatives. His experiments, like those of other workers, are based on the premise that the sulphydryl group may be the key to therapeutically lasting results. And yet, in human beings, it seems to be a sign of senescence that cells proliferate uninhibitedly and thus form cancer colls.

The book culminates in the surmise that the balance of electron acceptors and donors is one of the crucial parameters of living substance. The author is also deeply convinced that two antagonistic substances, namely "promine" (for promoter) and "rotine" (for inhibitor), regulate cell division. So far retine has not been isolated, but glyoxalase seems to represent promine.

Szent-Györgyi writes with passion and like a visionary. There is something artistic about his presentation, notwithstanding his profound knowledge of biochemistry. His exeursions into physics may not always meet with the approval of the theoretical physicist, but one cannot deny that his views are original and often fascinating. His publications are always ovents of tremendous impact upon the reader. This book is witness that the old warrior in the realm of biochemistry possesses still his full powers of imaginative reasoning and that he knows how to tell a narrative even when prosenting a scientific thesis. I think that every biochemist and biophysicist should ponder over the diverse messages manifested in this work.

WOLFGANG YoURGRaU

\section{A FEAST OF IMMUNOLOGY}

\section{Topics in Basic Immunology}

Edited by Michael Sela and Moshe Prywes. Pp. 180. (Academic Press: New York and London, August 1969.) $\$ 13.50$.

IF one is looking for a guide to present trends in basic immunology, one should certainly consult this publication, which contains a collection of articles by some of the world's leading immunologists. These have been published already, in a special edition of the Israel Journal of Medical Sciences, together with an appendix devoted to abstracts of the papers presented at the First Annual Meeting of the Israel Immunological Society. As a public relations exercise designed to "reflect ... the present status of immunological research in Israel" (to quote the editors' own words), the inclusion of the abstracts is understandable, but they waste valuablo space in a hardback publication and nobody would deny that immunology in Israel is thriving.

The principal papers are of a high standard. Many contain interesting new data as woll as valuable background information and stimulating discussions. Some concentrate on technical aspects, illustrating the high degree of sophistication reached by the present day immunologist in the development of new in vitro methods of studying interactions at both the molecular and 